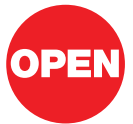

SUBJECT AREAS:

PERMEATION AND

TRANSPORT

PATCH CLAMP

HIGH-THROUGHPUT

SCREENING

ASSAY SYSTEMS

Received

21 December 2012

Accepted

21 January 2013

Published

6 February 2013

Correspondence and requests for materials should be addressed to M.P. (pusch@ge.ibf. cnr.it)

\title{
An optical assay of the transport activity of $\mathrm{ClC}-7$
}

\author{
Ilaria Zanardi, Giovanni Zifarelli \& Michael Pusch
}

Istituto di Biofisica, CNR, Via De Marini 6, 16149 Genoa, Italy.

Osteoporosis, characterized by excessive osteoclast mediated bone resorption, affects millions of people worldwide representing a major public health problem. $\mathrm{ClC}-7$ is a chloride-proton exchanger localized in lysosomes and in the resorption lacuna in osteoclasts where it is essential for bone resorption. Thus, drugs targeted at ClC-7 have been proposed for ameliorating osteoporosis. However, functional assays suited for high throughput screening (HTS) of ClC-7 function are lacking. Here we describe two complementary variants of purely optical assays of the transport activity of ClC-7, redirected to the plasma membrane employing a genetically encoded fluorescent $\mathrm{Cl}^{-} / \mathrm{pH}$ indicator fused to the $\mathrm{ClC}-7$ protein. These simple and robust functional assays of $\mathrm{ClC}-7$ transport are well-suited to be applied in HTS of small-molecule inhibitors and may help to develop drugs suited for the treatment of osteoporosis.

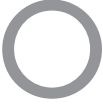

steoporosis, characterized by excessive osteoclast mediated bone resorption, affects millions of people worldwide with predominance in women and elderly people, becoming a major public health problem ${ }^{1}$. The increase in the proportion of elderly people will have a dramatic impact on health care costs since it is expected that the number of osteoporotic fractures will double over the next 50 years ${ }^{1}$. In osteoporosis an imbalance of osteoblast mediated bone formation and osteoclast mediated bone resorption leads to progressive loss of bone mass and results in bone fragility ${ }^{2}$. Bone resorption is directed by osteoclasts that release protons and proteases in the resorption lacunae causing the dissolution of hydroxyapatite, and the cleavage of matrix proteins ${ }^{3}$. The acidification of the resorption lacunae, as in lysosomes, depends on chloride. Chloride ions have been proposed to maintain the electro-neutrality providing negative charges when protons are released in the lacuna and permits an efficient decrease of $\mathrm{pH}^{4}$, but the precise role of the $\mathrm{Cl}^{-}$transport into the resorption lacuna is not clear $^{5}$. Several approaches for the treatment of osteoporosis are currently available ${ }^{6}$ allowing diverse therapy strategies but initially rather effective treatments are associated sometimes with unwanted side-effects ${ }^{7}$. Thus, novel effective drugs for the treatment of osteoporosis may have a significant positive impact. A promising pharmacological target is the lysosomal $\mathrm{Cl}^{-} / \mathrm{H}^{+}$exchanger $\mathrm{ClC}-7^{8}$. Loss of function of $\mathrm{ClC}-7$, or of its associated beta subunit Ostm1, in man and mice lead to osteopetrosis, neurodegeneration and lysosomal storage disease ${ }^{9-13}$. The osteopetrotic phenotype is explained by the fact that the ion transport activity of $\mathrm{ClC}-7$ is essential for the osteoclast mediated bone resorption. Conversely, osteoporosis is caused by excessive bone resorption. Thus, reducing bone resorption by blocking $\mathrm{ClC}-7$ activity can be expected to provide a highly effective treatment of osteoporosis $^{8}$.

ClC-7 associated with Ostm 1 is an intracellular chloride-proton exchanger member of the CLC protein family localized in lysosomes and in the ruffled border of osteoclasts. Among anion-transporting CLC proteins some function as passive $\mathrm{Cl}^{-}$channels and others work as active anion/proton antiporters with a stoichiometry of twoanions: one-proton ${ }^{14,15}$. Human $\mathrm{ClC}-1, \mathrm{ClC}-2, \mathrm{ClC}-\mathrm{Ka}$, and $\mathrm{ClC}-\mathrm{Kb}$, are chloride ion channels expressed on the plasma membrane, whereas ClC-3, ClC-4, ClC-5, ClC-6, and ClC-7 are intracellular $\mathrm{Cl}^{-} / \mathrm{H}^{+}$antiporters localized mostly in endosomal and lysosomal membranes ${ }^{16}$.

The lysosomal localization of ClC-7 precludes a classic electrophysiological approach for the investigation of its functional characteristics. Recently, however, the disruption of a leucine motif within the cytoplasmic N-terminus resulted in a partial plasma membrane redirection of the transporter ${ }^{17}$. Exploiting this mutation, allowed Leisle et al. ${ }^{18}$ to characterize the biophysical properties of $\mathrm{ClC}-7$ revealing a slow voltage dependent activation at voltages more positive than $\sim 20 \mathrm{mV}$ and establishing a $2 \mathrm{Cl}^{-} / 1 \mathrm{H}^{+}$exchange stoichiometry similar to $\mathrm{ClC}-4$ and $\mathrm{ClC}-5$, the prokaryotic $\mathrm{ClC}-\mathrm{ec} 1$ and the nitrate/proton antiporter AtCLCa ${ }^{19-22}$.

Even though electrophysiology can be used to sharply investigate the characteristics of ion transporting membrane proteins, it is a time-consuming and labor-intensive technique and it is unlikely to be exploited in high throughput screening (HTS). An acid influx assay monitoring the effect of activation of the V-ATPase, in the 
presence of the potassium ionophore valinomycin (VAL) on human osteoclasts expressing $\mathrm{ClC}-7$ was recently developed by Jensen et $\mathrm{al}^{23}$. However, the complications related to the specific cell line required and the elaborate osteoclast membrane vesicle preparation render also this method hard to be used in HTS.

Here, we describe a purely optical assay of $\mathrm{ClC}-7 / \mathrm{Ostm} 1$ function employing the $\mathrm{E}^{2} \mathrm{GFP} / \mathrm{DsRed} \mathrm{Cl}^{-} / \mathrm{pH}$ sensor ${ }^{24}$ fused to the Cterminus of $\mathrm{ClC}-7$. The assay can be easily miniaturized and transformed for a use in HTS.

\section{Results}

Localization and functionality of Ostm1-2AP-wtClC-7 $7^{\mathrm{PM}}-\mathrm{E}^{2} \mathrm{GFP} /$

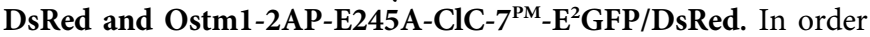
to develop a functional optical assay of the $\mathrm{ClC}-7$ transporter we exploited the recently developed GFP-based biosensor $E^{2} \mathrm{GFP} /$
DsRed, which allows to measure simultaneously the concentration of protons and $\mathrm{Cl}^{-}$ions, employing fluorescence excitation at three different wavelength $s^{24}$. The sensor is a fusion of two independent fluorophores: a $\mathrm{pH}$ and $\left[\mathrm{Cl}^{-}\right]$sensitive GFP variant (E $\mathrm{GFP}$ ) and the $\mathrm{pH}$ and $\mathrm{Cl}^{-}$insensitive red fluorescent $\mathrm{DsRed}^{24}$. In order to reduce the number of constructs to co-express, and to localize the $\mathrm{Cl}^{-} / \mathrm{H}^{+}$ sensor as close as possible to the transporter itself, we fused the $\mathrm{E}^{2} \mathrm{GFP} / \mathrm{DsRed}$ sensor to the cytoplasmic C-terminus of $\mathrm{ClC}-7$, which did not alter the functional properties of $\mathrm{ClC}-7$ (see below). WT ClC-7 strictly localizes to lysosomes/late endosomes ${ }^{5,10,11}$ but recently Stauber et al. ${ }^{17}$ identified an $\mathrm{N}$-terminal leucine based sorting motif that, when mutated (L23A-L24A-L36A-L37A; "ClC-7 ${ }^{\mathrm{PM} \text { ") }}$ redirects a significant proportion of the transporter to the plasma membrane and renders it more accessible for functional studies $^{17,18}$. Consequently, we introduced these mutations in the a
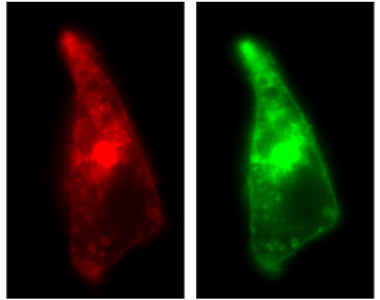

C

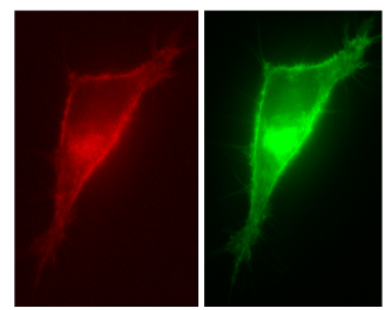

b

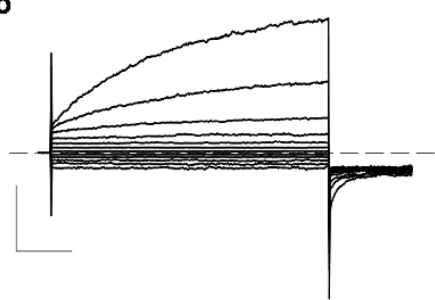

d
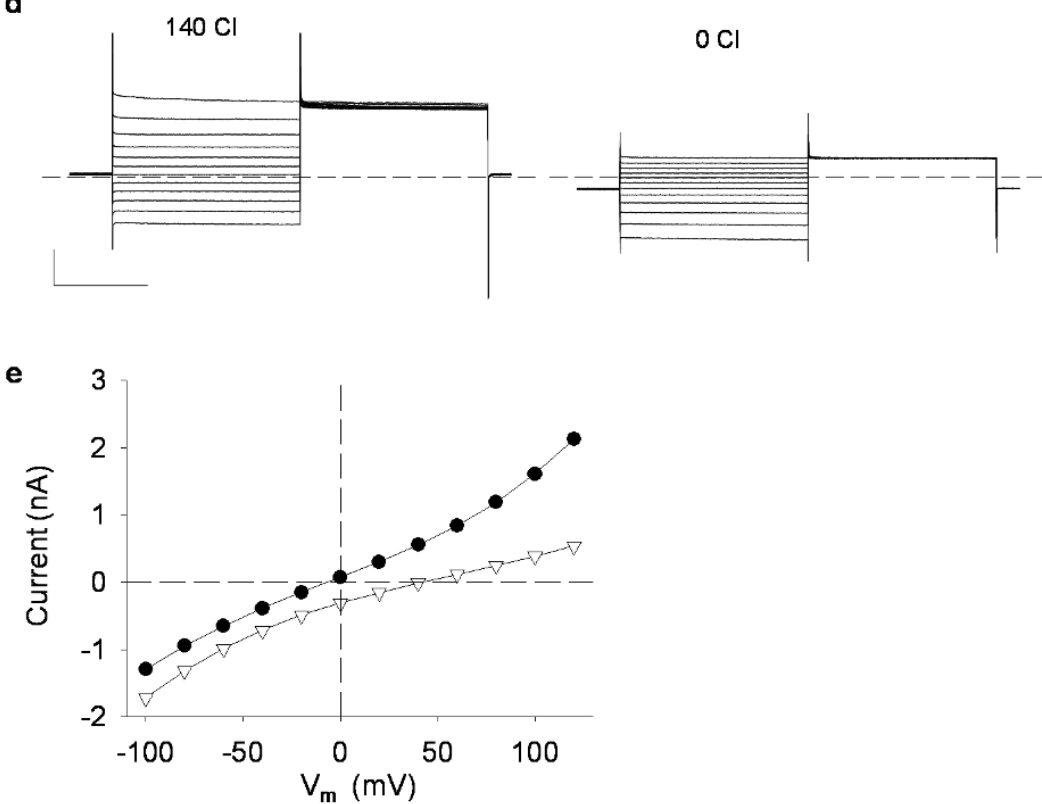

Figure $1 \mid$ Ostm1-2AP-wtClC-7 ${ }^{\mathrm{PM}}-\mathrm{E}^{2} \mathrm{GFP} / \mathrm{DsRed}$ and Ostm1-2AP-E245A-ClC-7 ${ }^{\mathrm{PM}}-\mathrm{E}^{2} \mathrm{GFP} / \mathrm{DsRed}$ are localized in the plasma membrane and are functional. (a) DsRed (red) and $\mathrm{E}^{2} \mathrm{GFP}$ (green) fluorescence in cells transiently transfected with Ostm1-2AP-wtClC-7 ${ }^{\mathrm{PM}}-\mathrm{E}^{2} \mathrm{GFP} / \mathrm{DsRed}$. (b) typical whole-cell currents from Ostm1-2AP-wtClC- $7^{\mathrm{PM}}-\mathrm{E}^{2} \mathrm{GFP} / \mathrm{DsRed}$ transfected HEK293 cells recorded using patch-clamp technique. Vertical scale bar represent $1 \mathrm{nA}$, horizontal $200 \mathrm{~ms}$. (c) fluorescence of DsRed (red) and $\mathrm{E}^{2} \mathrm{GFP}$ (green) partially localizes in the plasma membrane in Ostm1-2AP-E245AClC- $7^{\mathrm{PM}}-\mathrm{E}^{2} \mathrm{GFP} / \mathrm{DsRed}$ transfected cells. (d) patch-clamp recordings of characteristic whole-cell currents elicited from Ostm1-2AP-E245A-ClC-7 $7^{\mathrm{PM}}$ $\mathrm{E}^{2} \mathrm{GFP} / \mathrm{DsRed}$ expressing cells in the presence of $140 \mathrm{mM} \mathrm{Cl}$ in the external solution (top panel), and after removal of extracellular chloride (bottom panel). Vertical scale bar represent $1 \mathrm{nA}$, horizontal $200 \mathrm{~ms}$. 
constructs for our assay. Functional expression of $\mathrm{ClC}-7$ requires the presence of the beta subunit Ostm $1^{12,18,25}$. To additionally reduce the number of different $\mathrm{cDNAs}$ to transfect and to ensure the simultaneous and equivalent expression of $\mathrm{ClC}-7 \mathrm{P}^{\mathrm{PM}}-\mathrm{E}^{2} \mathrm{GFP} /$ DsRed and Ostm1, we constructed a plasmid in which the two cDNAs are linked by a self-cleavable $2 \mathrm{~A}$ peptide. The $2 \mathrm{~A}$ peptide mediates a co-translational cleavage producing multiple proteins from a polyprotein encoded by a single open reading frame ${ }^{26}$.

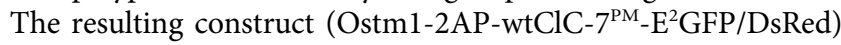
was fully functional in Xenopus oocytes (Supplementary Fig. 1) and in transfected HEK cells (Fig. 1) showing the expected partial plasma membrane expression of the fusion protein (Fig. 1a). Transfected HEK cells were also tested for functional expression using the patch-clamp technique yielding slowly activating outwardly rectifying currents at positive voltages $>=20 \mathrm{mV}$ as described by Leisle et al. ${ }^{18}$ (Fig. 1b).

The strong voltage-dependence poses a severe problem for a nonelectrophysiological assay of $\mathrm{ClC}-7$ function, because it is not trivial to clamp the plasma membrane at a positive voltage, for example by using ionophores or K-depolarization, which results at most in a voltage around $0 \mathrm{mV}$. To circumvent this problem, we adopted two different strategies. In a first approach, we additionally introduced a mutation of the gating glutamate (E245A) which renders the transporter voltage-independent and which abolishes proton transport $^{18}$. Also this construct (Ostm1-2AP-E245A-ClC-7 ${ }^{\text {PM }}-E^{2}$ GFP/ DsRed) was fully functional in oocytes (Supplementary Fig. 2) and in transfected HEK cells (Fig. 1c, d). The outwardly directed current component was abolished when the extracellular chloride was removed and a shift of the reversal potential to more positive values was observable as expected from a chloride-selective current and in agreement with previous studies (Fig. 1e) ${ }^{18}$. These constitutive, voltage-independent currents of the gating glutamate mutant render it amenable to the $\mathrm{Cl}^{-}$flux assay described below.

Development of the $\mathrm{Cl}^{-}$flux assay exploiting $\mathrm{ClC}-1$ transport activity. In order to be able to test the $\mathrm{Cl}^{-}$flux assay with a blocking compound we first screened several commonly used chloride channel blockers on the gating glutamate mutant (E245A) expressed in Xenopus oocytes. Unfortunately, none of these compounds showed inhibitory activity with an EC-50 below $0.5 \mathrm{mM}$ (Supplementary Table 1) with the most potent substance being RT-9327, which has an EC-50 of $0.8 \mathrm{mM}$, too large to be useful as a test compound.

Thus, in the absence of a suitable positive control, we set-up the assay using as a surrogate the plasma membrane localized ClC-1 chloride channel ${ }^{28}$ which is specifically blocked by 9 -anthracene carboxylic acid (9-AC) ${ }^{29}$. As for ClC-7, E ${ }^{2}$ GFP/DsRed was fused to the cytoplasmic C-terminus of $\mathrm{ClC}-1$ (Fig. 2a) and the functional expression of the channel in transiently transfected HEK293A cells was controlled using the patch-clamp technique (data not shown). As a negative control we transfected HEK293A cells with the soluble $\mathrm{E}^{2} \mathrm{GFP} / \mathrm{DsRed}$ sensor localizing in the cytoplasm (Fig. 2b).

The basic idea of the assay is to abruptly reduce the extracellular chloride concentration $\left(\left[\mathrm{Cl}^{-}\right]_{\text {ext }}\right)$ and to monitor the resulting $\mathrm{ClC}-1$ mediated decrease of the intracellular chloride concentration $\left(\left[\mathrm{Cl}^{-}\right]_{\text {int }}\right)$ that leads to an increase of the $\mathrm{E}^{2} \mathrm{GFP}$ fluorescence (via a reduced static quenching) by measuring the $\mathrm{E}^{2} \mathrm{GFP} / \mathrm{DsRed}$ fluorescence ratio. A critical feature of the assay is to carefully adjust the osmolarity of the solutions (by adding mannitol) to avoid the activation of endogenous volume regulated anion channels $\left(\right.$ VRAC) ${ }^{30}$. In order to provide a sustained driving force for chloride exit the potassium ionophore valinomycin (VAL) was added to the solutions.

Fluorescence was excited a $458 \mathrm{~nm}$ and $482 \mathrm{~nm}$ (for $\mathrm{E}^{2} \mathrm{GFP}$ ) and $563 \mathrm{~nm}$ (for DsRed ) and emission of the $\mathrm{E}^{2} \mathrm{GFP}$ fluorescence and DsRed fluorescence was split using a dual view configuration (Till photonics) and images were recorded with a EXI Blue camera a

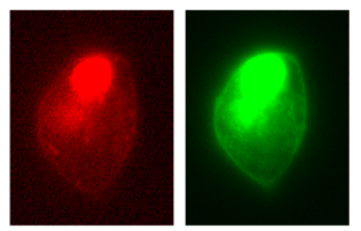

b
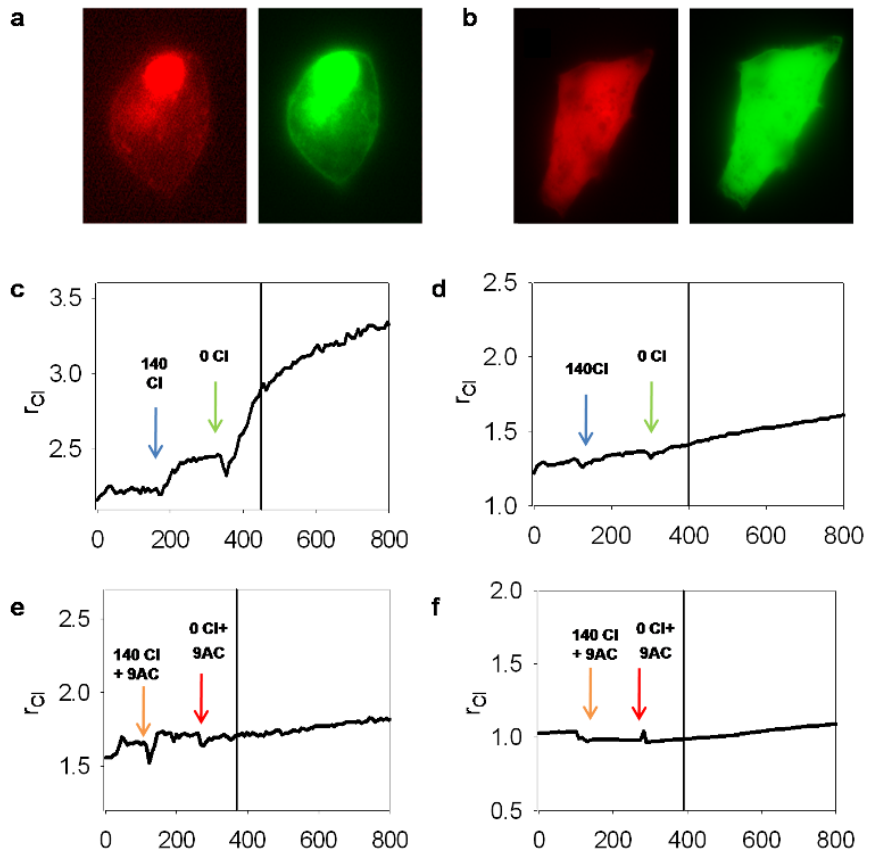

Time (sec)
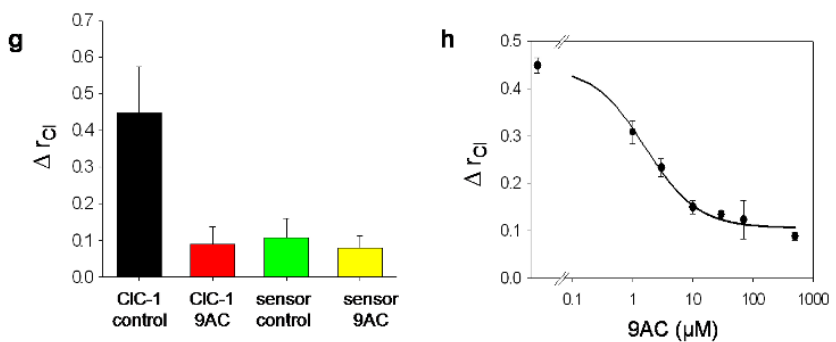

Figure $2 \mid \mathrm{Cl}^{-}$flux assay detects ClC-1 transport activity. Plasma membrane localized fluorescence of DsRed (red) and $\mathrm{E}^{2} \mathrm{GFP}$ (green) in ClC-1-E ${ }^{2}$ GFP/DsRed transfected HEK cells (a) and cytosolic diffused fluorescence in cells transfected with soluble $E^{2}$ GFP/DsRed (b). Effect of the change in $\left[\mathrm{Cl}^{-}\right]_{\text {ext }}$ from $140 \mathrm{mM}$ to $0 \mathrm{mM}$ on $\mathrm{r}_{\mathrm{Cl}}$ on a single cell expressing ClC-1-E ${ }^{2}$ GFP/DsRed (c) or soluble E ${ }^{2}$ GFP/DsRed (d). Effect of $500 \mu \mathrm{M} 9$-AC on the change in $r_{\mathrm{Cl}}$ in cells expressing ClC-1-E ${ }^{2} \mathrm{GFP} / \mathrm{DsRed}$ (e) or soluble $E^{2} G F P / D s R e d(f)$. Here and in all following figures, arrows indicate times of the solution change; vertical lines mark $100 \mathrm{~s}$ after the preceding solution change. Mean values of the change of $\mathrm{r}_{\mathrm{Cl}}$ at 100 seconds after the start of the perfusion with the $0 \mathrm{Cl}$ solution $(\mathrm{g})$. Dose response analysis of the effect of 9-AC on $\mathrm{r}_{\mathrm{Cl}}$ in ClC-1 expressing cells $(0 \mu \mathrm{M} 9$-AC: $\mathrm{n}$ $=67 ; 1 \mu \mathrm{M} 9$-AC: $\mathrm{n}=18 ; 3 \mu \mathrm{M} 9-\mathrm{AC}: \mathrm{n}=27 ; 10 \mu \mathrm{M} 9-\mathrm{AC}: \mathrm{n}=25 ; 30 \mu \mathrm{M}$ 9-AC: $\mathrm{n}=25 ; 70 \mu \mathrm{M} 9-\mathrm{AC}: \mathrm{n}=4 ; 500 \mu \mathrm{M} 9-\mathrm{AC} \mathrm{n}=36$; Error $=$ SEM) $(\mathrm{h})$.

(QImaging Retiga). Images were recorded at $\sim 0.1 \mathrm{~Hz}$ while the transfected cells were exposed to a drop in $\left[\mathrm{Cl}^{-}\right]_{\text {ext }}$ (from $140 \mathrm{mM}$ to $0 \mathrm{mM}$, in the continued presence of $100 \mu \mathrm{M}$ valinomycin). In order to optimize the throughput of the screening assay using the iMIC microscope we exploited the possibility of the system to memorize a large number of positions $(x-y-z)$ of the microscope stage ( $x-$ $y)$ and objective height $(\mathrm{z})$, to be able to scan a relatively large number of cells from the same culture dish, each at the single cell level. Following the abrupt decrease in $\left[\mathrm{Cl}^{-}\right]_{\text {ext }}$ we observed a gradual increase of $\mathrm{r}_{\mathrm{Cl}}\left(\mathrm{r}_{\mathrm{Cl}}=\mathrm{F} 458 / \mathrm{F} 563\right)$ in ClC-1-E ${ }^{2} \mathrm{GFP} /$ DsRed expressing cells (Fig. 2c) but not in cells transfected with the soluble $\mathrm{E}^{2} \mathrm{GFP} /$ DsRed (Fig. 2d). Addition of 9-AC (500 $\mu \mathrm{M})$, a specific blocker of $\mathrm{ClC}-1$, eliminated the fluorescence increase in ClC-1 transfected cells (Fig. 2e) and had no effect in $E^{2}$ GFP/DsRed expressing cells (Fig. 2f). To quantify the fluorescence changes we calculated the change of $\mathrm{r}_{\mathrm{Cl}}$ at 100 seconds after the start of the perfusion with the $0 \mathrm{Cl}$ solution 
(Fig. 2g). A dose response analysis of the blocking effect of 9-AC (Fig. $2 \mathrm{~h}$ ) was conducted revealing an EC-50 value of $\sim 1.6 \mu \mathrm{M}$, in good agreement with electrophysiological results ${ }^{29}$. These results confirm that the fluorescence change reflects specific chloride transport through $\mathrm{ClC}$ 1 , and, importantly, that the assay is suitable for the investigation of the modulation effect of putative activators or blockers on the activity of a chloride transporting protein expressed in the plasma membrane.

Application of the $\mathrm{Cl}^{-}$flux assay on the gating glutamate mutant E245A. We next tested the assay on the gating glutamate mutant of ClC-7. HEK 293A cells transiently expressing Ostm1-2AP-E245A$\mathrm{ClC}-7^{\mathrm{PM}}-\mathrm{E}^{2} \mathrm{GFP} / \mathrm{DsRed}$ were exposed to a decrease in $\left[\mathrm{Cl}^{-}\right]_{\text {ext }}$ as described above. A considerable increase of $\mathrm{r}_{\mathrm{Cl}}$ was observed, comparable to that seen with $\mathrm{ClC}-1-\mathrm{E}^{2} \mathrm{GFP} / \mathrm{DsRed}$ (Fig. 3a). The change of $\mathrm{r}_{\mathrm{Cl}}$ following the perfusion with the $0 \mathrm{Cl}$ solution was calculated after 100 seconds and is summarized in Fig. $3 \mathrm{~b}$.

A remarkable increase of $\mathrm{pH}$ related fluorescence is caused by $\mathrm{ClC}$ 7 mediated transport driven by the activation of $\mathrm{FaNaCh}$. In a second strategy, we sought to establish a simple assay also for the WT protein by the additional inclusion of a strongly depolarizing agent. $\mathrm{K}^{+}$depolarization, but also optogenetic tools, would allow a depolarization to at most $0 \mathrm{mV}$, insufficient for activation of ClC-7. In contrast, activation of a $\mathrm{Na}^{+}$selective channel might provide sufficient positive membrane voltage to drive $\mathrm{ClC}-7$ mediated transport. We thus co-expressed Ostm1-wtClC- $7^{\mathrm{PM}}-\mathrm{E}^{2} \mathrm{GFP} / \mathrm{DsRed}$ with the peptide gated sodium channel $\mathrm{FaNaCh}$, which is specifically activated by the small peptide FMRFamide ${ }^{31}$. A similar strategy has already been employed to activate the depolarization activated CLC5 transporter ${ }^{19}$. HEK cells co-transfected with the two constructs were tested for functional expression of both Ostm1-2AP-wtClC$7^{\mathrm{PM}}-\mathrm{E}^{2} \mathrm{GFP} / \mathrm{DsRed}$ and $\mathrm{FaNaCh}$ using the patch-clamp technique (data not shown). Despite the relatively large buffer capacity of the cytosol, transport mediated by $\mathrm{ClC}-7$ is expected to produce a larger relative change in the intracellular proton concentration than in the intracellular $\mathrm{Cl}^{-}$concentration. We thus concentrated on the fluorescence ratio $\mathrm{F} 482 / \mathrm{F} 458=\mathrm{r}_{\mathrm{pH}}$, which directly reflects changes in $\mathrm{pH}$ and is insensitive to changes in $\mathrm{Cl}^{-24}$. Indeed, a striking increase of $\mathrm{pH}$ related fluorescence was observable when HEK cells expressing Ostm1-2AP-wtClC-7 $7^{\mathrm{PM}}-\mathrm{E}^{2} \mathrm{GFP} / \mathrm{DsRed}$ and $\mathrm{FaNaCh}$ were perfused with a solution containing FMRFamide (Fig. 4a), while the $\mathrm{Cl}^{-}$related fluorescence ratio changed only slightly (Supplementary Fig. 3). No change in fluorescence was detected applying the same conditions to cells transfected with Ostm1-2APwtClC-7 ${ }^{\text {PM }}-E^{2}$ GFP/DsRed but without FaNaCh (Fig. 4b). The change of $r_{\mathrm{pH}}$ at 100 seconds after the start of the perfusion with FMRF provides a robust readout of functional ClC-7 activity (Fig. 4c).

\section{Discussion}

Plasma membrane ion channels and ion transporters are difficult targets for high-throughput screening assays. Intracellular ion transporters are even more challenging, but these proteins represent an almost untapped class of drug targets. Among these is the lysosomal ClC-7 $\mathrm{Cl}^{-} / \mathrm{H}^{+}$antiporter, a promising target to treat osteoporosis ${ }^{8}$. Here we report the development of simple all-optical assays, which provide robust signals of ClC-7/Ostm1 function based on the $\mathrm{E}^{2} \mathrm{GFP} /$ DsRed $\mathrm{Cl}^{-} / \mathrm{pH}$ sensor. The creation of constructs ensuring the equivalent and simultaneous expression of Ostm 1 and $\mathrm{ClC}-7$ in the plasma membrane, employing $\mathrm{ClC}-7$ sorting mutants ${ }^{17}$ and selfcleavable peptides ${ }^{26}$ successfully solved the problem of the tricky measure of an intracellular membrane protein that compulsorily needs a beta subunit to be active. The fusion of the biosensor to the C-terminus does not modify the functional properties and the 2AP construct is able to mediate the expression of both the Ostm 1 and the $\mathrm{ClC}-7$ protein.

We applied two alternative strategies to cope with the problem that the transporter is activated only at large positive voltages. Firstly, we mutated the conserved gating glutamate to alanine which eliminates the voltage dependence and renders $\mathrm{ClC}-7$ a passive $\mathrm{Cl}^{-}$conductance. For this E245A mutant we established a $\mathrm{Cl}^{-}$flux assay, which provides a simple readout of the transport function. To test the assay we used the $\mathrm{ClC}-1 \mathrm{Cl}^{-}$channel as a surrogate for which relatively high affinity blocker are available. For this channel the assay provided an accurate and robust readout of the pharmacological sensitivity of the channel.

Since the uncoupling mutant maintains the basic chloride permeation pathway it can be expected that drugs that block the E245A mutant will also inhibit the WT protein with a similar efficacy, but not the other way round. For example, drugs that interfere with the mechanism of the voltage-dependence might block the WT protein but not the uncoupling mutant. We thus sought an alternative assay for the WT transporter. To achieve a sufficient depolarization of the cell we co-expressed ClC-7 together with the peptide gated $\mathrm{Na}^{+}$ channel $\mathrm{FaNaCh}$, and measured the resulting intracellular alkalinization caused by the $\mathrm{Cl}^{-} / \mathrm{H}^{+}$antiport triggered by the application of the FMRF peptide.

Thus, we developed two complementary, all-optical assays for $\mathrm{ClC}-7$ function, ready to be used in a pharmacological screening for $\mathrm{ClC}-7$ inhibitors.

Nevertheless both assays can be further simplified for the adaption in miniaturized HTS assays. A first simplification regards the FaNaCh based assay in which two cDNAs have to be co-transfected and the $\mathrm{FaNaCh}$ protein expression is not visually possible. One solution could be the construction of viral vectors to assure a uniform and high-yield FaNaCh expression. Alternatively, the FaNaCh ORF a

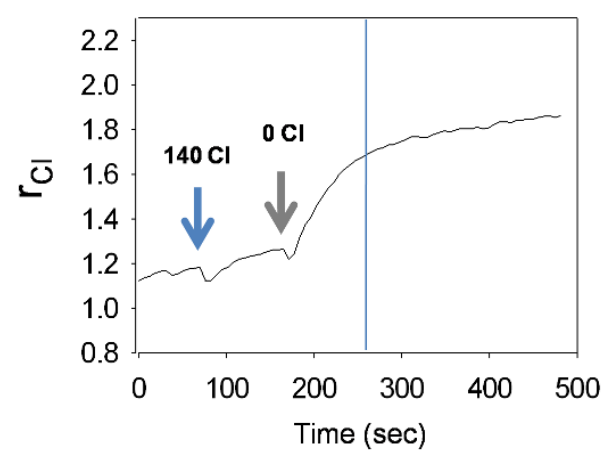

b

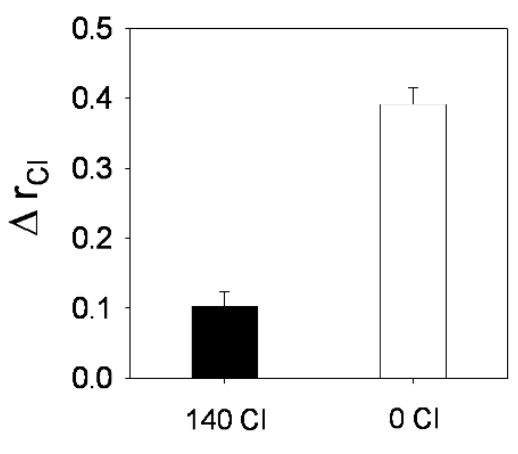

Figure $3 \mid \mathrm{Cl}^{-}$flux assay for the gating glutamate mutant E245A. Effect of the change in $\left[\mathrm{Cl}^{-}\right]_{\text {ext }}$ from $140 \mathrm{mM}$ to $0 \mathrm{mM}$ on $\mathrm{r}_{\mathrm{Cl}}$ on a single cell expressing Ostm1-2AP-E245A-ClC-7 ${ }^{\mathrm{PM}}-\mathrm{E}^{2} \mathrm{GFP} / \mathrm{DsRed}$ (a). Average values of the change of $\mathrm{r}_{\mathrm{Cl}}$ at 100 seconds after the start of the perfusion with the indicated solutions ( $140 \mathrm{Cl}: \mathrm{n}=19 ; 0 \mathrm{Cl}: \mathrm{n}=26$; Error $=\mathrm{SEM})(\mathrm{b})$. 
a

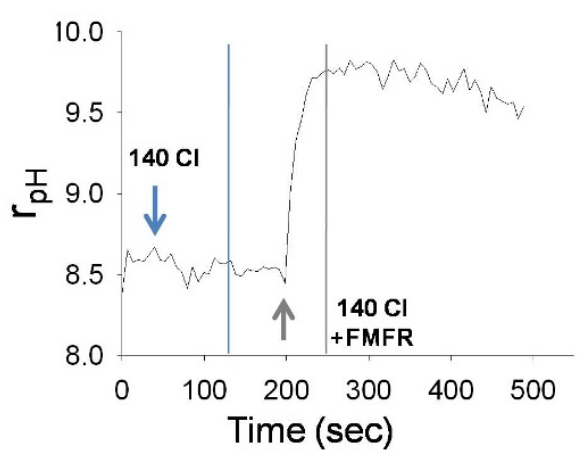

b

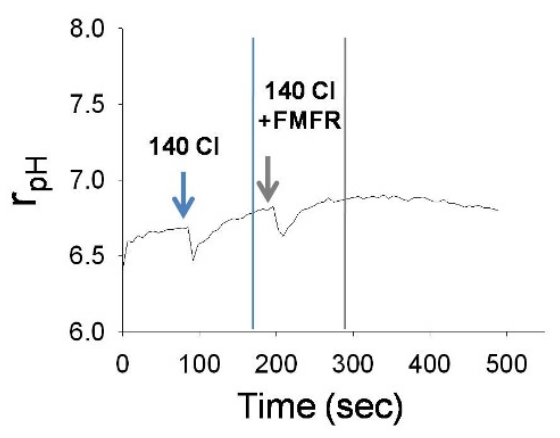

C

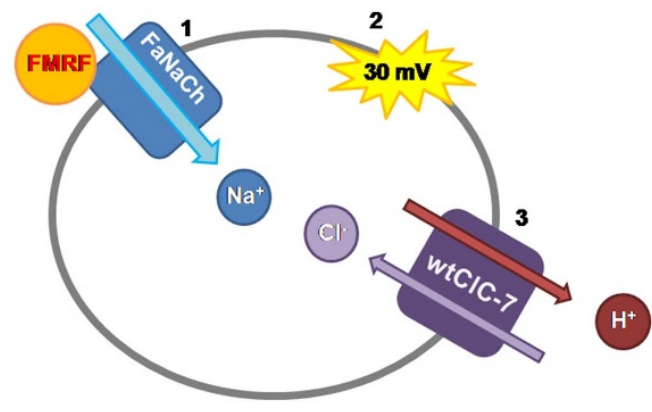

d

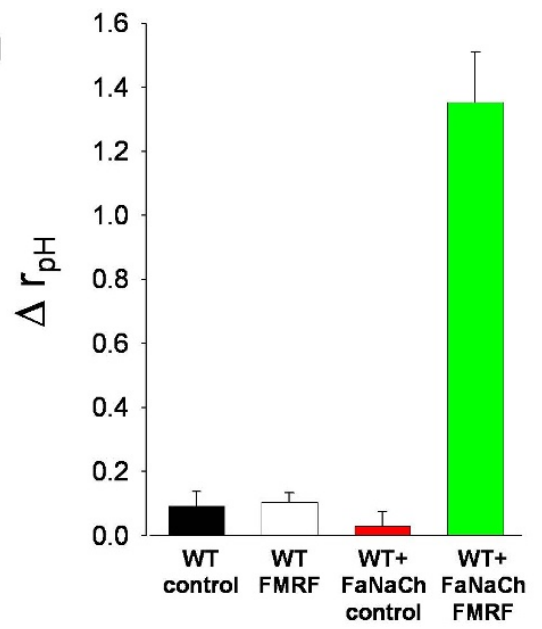

Figure $4 \mid \mathrm{ClC}-7$ mediated transport driven by the activation of $\mathrm{FaNaCh}$ causes a remarkable increase of $\mathrm{pH}$ related fluorescence. Effect of $30 \mu \mathrm{M}$ FMRF on $\mathrm{r}_{\mathrm{pH}}$ on single cells expressing Ostm1-2AP-wtClC- $7^{\mathrm{PM}}-\mathrm{E}^{2} \mathrm{GFP} / \mathrm{DsRed}$ and FaNaCh (a) or Ostm1-2AP-wtClC- $7^{\mathrm{PM}}-\mathrm{E}^{2} \mathrm{GFP} / \mathrm{DsRed}$ alone (b). Scheme of the mechanism of the stimulation of ClC-7 transport by FaNaCh activation (c). Mean values of the changes of $\mathrm{r}_{\mathrm{pH}}$ at 100 seconds after the addition of FMRF (WT control: $\mathrm{n}=31$; WT FMRF: $\mathrm{n}=31$; WT+FaNaCh control: $\mathrm{n}=24$; WT+FaNaCh FMRF: $\mathrm{n}=25$; Error $=$ SEM) $(\mathrm{d}$ ).

could be joined onto the Ostm1-2AP-wtClC-7PM-E2GFP/DsRed construct using a second $2 \mathrm{~A}$ peptide, insuring contemporaneous expression after transient transfection easily revealed by the presence of the $\mathrm{E}^{2} \mathrm{GFP} / \mathrm{DsRed}$ fluorescence.

Several simplifications of the optical system can be considered for both assays. For the $\mathrm{Cl}^{-}$flux assay (using the E245A mutant), it is not necessary to record $\mathrm{pH}$ changes and thus it is possible eliminate the $\mathrm{E}^{2} \mathrm{GFP}$ excitation at the $\mathrm{pH}$ sensitive wavelength $(482 \mathrm{~nm})$. For the $\mathrm{FaNaCh}$ based alkalinization assay it is not necessary to record changes in the chloride concentration, and thus, the excitation and emission of the DsRed fluorescence can be eliminated. Consequently, in this second case it is also possible to simplify the fluorescence sensor eliminating the DsRed part. With these simplifications the assays could for example be implemented on a microplate reader necessitating two excitation frequencies, one or two emission lines and one solution application step for each assay. Applying both assays in parallel has the further advantage that positive hits emerging in one of the assays can be cross validated by the other one, providing hints on the mechanism of action of potential $\mathrm{ClC}-7$ blockers.

\section{Methods}

Molecular biology and transient DNA expression. The N-terminal mutant (L23AL24A-L36A-L37A named ClC- $7^{\mathrm{PM}}$ ) of rat ClC- $7^{17,18}$ with the $\mathrm{E}^{2} \mathrm{GFP} / \mathrm{DsRed} \mathrm{Cl}^{-} / \mathrm{pH}$ sensor ${ }^{24}$ fused to the C-terminus ${ }^{25}$, mouse Ostm1 and ClC-1-E ${ }^{2}$ GFP/DsRed (C-term) were in pFrog, a pCDNA3 derived vector suitable for transient expression in HEK293 cells. The E245A mutant of ClC-7 was introduced into the background of $\mathrm{ClC}-7^{\mathrm{PM}}$ $\mathrm{E}^{2} \mathrm{GFP} / \mathrm{DsRed}-\mathrm{pFROG}{ }^{25}$. In new constructs we fused Ostm1 and ClC-7 $7^{\mathrm{PM}}-\mathrm{E}^{2} \mathrm{GFP} /$ DsRed or ClC- $7^{\text {PM }}-\mathrm{E} 245 \mathrm{~A}-\mathrm{E}^{2} \mathrm{GFP} / \mathrm{DsRed}$ using the $2 \mathrm{~A}$ peptide sequence coded by GGCAGTGGAGAGGGCAGAGGAAGTCTGCTAACATGCGGTGACGTCGA GGAGAATCCTGGCCCA ${ }^{26}$. To this end we designed two overlapping 60 bp long primers. The forward primer started with the last two thirds of the 2AP sequence (in bold in the primer sequence) and ended with the 21 starting bases of ClC-7 (in italic in the primer sequence) (2AP-rC7E²GFPDsRed_F: GTCTGCTAACATGCG GTGACGTCGAGGAGAATCCTGGCCCAATGGCCAACGTTTCTAAGAA). The reverse primer partially overlapped the forward primer (underlined) in the 2AP part (bold) and included the 21 final bases of Ostm1 (in italic), excluding the stop codon (2Ap-OSTM1_R: CACCGCATGTTAGCAGACTTCCTCTGCCCTC

TCCACTGCCGGTGGCATTTTCTTGAATGT). These two primers were used in separate reactions with external primers within Ostm1 and ClC-7 respectively and the two PCR products were combined in a recombinant PCR employing the external primers. The resulting PCR-product was inserted into pFROG with specific restriction reactions in frame with Ostm1 and ClC- $7^{\mathrm{PM}^{\mathrm{M}}}-\mathrm{E}^{2} \mathrm{GFP} / \mathrm{DsRed}$.

The original clones of ClC-7 and Ostm1 were kindly provided by T.J. Jentsch. FaNaCh from Helix asperga in the pBSK vector was obtained from E. Lingueglia.

Transient transfection in HEK293 cells was performed using the Effectene Transfection Reagent Kit (Qiagen, cat. \# 301425) according to manufacturer's instructions. For oocyte expression the same constructs were cloned into the PTLN vector ${ }^{33}$. All constructs were expressed by injecting $25-50 \mathrm{ng}$ of cRNA transcribed from linearized cDNA using the Ambion mMessage mMachine SP6 kit. Oocytes maintenance solution contained (in $\mathrm{mM}$ ) $90 \mathrm{NaCl}, 10 \mathrm{HEPES}, 2 \mathrm{KCl}, 1 \mathrm{MgCl}_{2}$, $1 \mathrm{CaCl}_{2}, \mathrm{pH} 7.5$. Oocytes were kept at $18{ }^{\circ} \mathrm{C}$ for $3-6$ days.

Cell Growth and Harvesting. HEK 293 cells were purchased from Invitrogen and maintained in $25 \mathrm{~cm}^{2}$ flasks in a cell growth medium composed of 90\% D-MEM high-glucose, Na-Pyruvate and L-Glutamine (Euroclone, ECM0728L), 10\% FBS (Sigma), 1\% Pen-Strep (Sigma). For fluorescence measurements, cells were seeded on polylysine treated $3 \mathrm{~cm}$ diameter glass-bottom petri dish chambers. These dishes were manufactured in the IBF Mechanical Workshop by gluing a round $22 \mathrm{~mm}$ diameter cover glass to a holed petri dish using Sylgard.

Electrophysiology. In accordance with national guidelines, oocytes were collected from Xenopus females anaesthetized with tricaine. After surgery, frogs were allowed to recover from anesthesia and suitable aftercare was given. For two-electrode voltage clamp recordings, the standard extracellular solution contained (in $\mathrm{mM}$ ): $100 \mathrm{NaCl}$, $5 \mathrm{MgSO}_{4}, 10$ Hepes, $\mathrm{pH}$ 7.3. Chloride was changed by substitution of $\mathrm{NaCl}$ with NaGlutamate. For all the recordings the pulse protocol consisted of voltage steps of $100 \mathrm{~ms}$ from -140 to $60 \mathrm{mV}$ with $20 \mathrm{mV}$ increments from a holding potential of $-20 \mathrm{mV}$, preceded by a $50 \mathrm{~ms}$ conditioning prepulse to $60 \mathrm{mV}$ and followed by a $50 \mathrm{~ms}$ postpulse to $-100 \mathrm{mV}$. For patch-clamp the standard extracellular solutions 
contained (in mM) $\left(\right.$ Gluc $=$ Gluconate): $140 \mathrm{Cl}$ solution: $140 \mathrm{NaCl}, 2 \mathrm{MgSO}_{4}, 2 \mathrm{CaCl}_{2}$, and $10 \mathrm{HEPES} / \mathrm{NaOH}$ (pH 7.3). $0 \mathrm{Cl}$ solution: $140 \mathrm{mM} ~ \mathrm{NaGluc}, 3 \mathrm{MgSO}_{4}, 2$ CaGluc, $10 \mathrm{HEPES} / \mathrm{NaOH}$ (pH 7.3). Intracellular solution was (in mM) $130 \mathrm{NaCl}, 2 \mathrm{MgSO}_{4}$, 2 EGTA, and $10 \mathrm{HEPES} / \mathrm{NaOH}(\mathrm{pH} 7.3)$. All recordings were performed in the whole-cell configuration using an EPC7 amplifier and the custom data acquisition program GePulse.

Fluorescence assay. The optical system is composed of a basic iMIC microscope with a QImaging Retiga EXI Blue camera and a dual-view port for the emission allowing the separation of the GFP and DsRed emissions (Till Photonics). For excitation we used Till Oligochrome a wavelength-switching device containing a stable Xenon light-source. Because of a slight imperfection, likely to be caused by a mechanical slip of the petri dish in the microscope fitting, the localization of the cells was slightly variable during time. This problem was resolved by adjusting our (self written) analysis software, developing a simple tracking feature. In this way up to 15 cells could be assayed in parallel for a single application of substances. The transfected cells were exposed to a change in $\left[\mathrm{Cl}^{-}\right]_{\text {ext }}(140 \mathrm{Cl}$ solution: $138 \mathrm{mM} \mathrm{NaCl}, 2 \mathrm{KCl}, 10 \mathrm{Hepes}$, 10 Glucose, $3 \mathrm{MgSO}_{4}, 1.8 \mathrm{CaCl}_{2}, \overline{\text { Mannitol } 100 \mathrm{mM}}$, Valinomycin $200 \mu \mathrm{M} ; 0 \mathrm{Cl}$ solution: $140 \mathrm{mM}$ NaGluc, 2 CaGluc, 10 Hepes, 10 Glucose, $3 \mathrm{MgSO}_{4}$, Mannito $\overline{100 \mathrm{mM}}$, Valinomycin $100 \mu \mathrm{M}$ while excited at $458 \mathrm{~nm}$ (100 msec exposition), $482 \mathrm{~nm}$ (30 msec exposition) and $563 \mathrm{~nm}$ (100 msec exposition). The iMIC filter GFP/DsRed and iMIC dichroic GFP/DsRed were used for all the acquisitions. The specific $\mathrm{ClC}-1$ blocker, 9-AC was dissolved in DMSO and added to the solution to the desired concentration (DMSO $<=0.1 \%$ ). For the experiments requiring $\mathrm{FaNaCh}$ activation, $30 \mu \mathrm{M}$ FMRFamide was added to the $140 \mathrm{Cl}$ solution. The $\mathrm{pH}$ of all solutions was titrated to 7.3. For the analysis we defined: $\mathrm{rCl}=\mathrm{F} 458 / \mathrm{F} 563$ and $\mathrm{r}_{\mathrm{pH}}=$ F482*3.33/F458. The factor 3.33 stems from the 3.33 fold shorter exposition at the (brighter) 482 excitation wavelength. Data analysis was performed with the custom analysis programs Anavision and Ana (freely available at http://users.ge.ibf.cnr.it/ pusch). A region of interest was drawn on the border of the analyzed cell and another on the background for background subtraction. Figures were prepared using SigmaPlot software.

1. Woolf, A. D. \& Pfleger, B. Burden of major musculoskeletal conditions. Bull World Health Organ 81, 646-656 (2003).

2. Raisz, L. G. Pathogenesis of osteoporosis: concepts, conflicts, and prospects. J. Clin. Invest. 115, 3318-3325 (2005).

3. Teitelbaum, S. L. Bone resorption by osteoclasts. Science 289, 1504-1508 (2000).

4. Baron, R., Neff, L., Louvard, D. \& Courtoy, P. J. Cell-mediated extracellular acidification and bone resorption: evidence for a low $\mathrm{pH}$ in resorbing lacunae and localization of a $100-\mathrm{kD}$ lysosomal membrane protein at the osteoclast ruffled border. J Cell Biol 101, 2210-2222 (1985).

5. Weinert, S. et al. Lysosomal pathology and osteopetrosis upon loss of $\mathrm{H}^{+}$-driven lysosomal $\mathrm{Cl}^{-}$accumulation. Science 328, 1401-1403 (2010).

6. Silverman, S. \& Christiansen, C. Individualizing osteoporosis therapy. Osteoporosis International 23, 797-809 (2012).

7. Kennel, K. A. \& Drake, M. T. Adverse effects of bisphosphonates: implications for osteoporosis management. Mayo Clin. Proc. 84, 632-637 (2009).

8. Schaller, S. et al. The chloride channel inhibitor NS3736 [corrected] prevents bone resorption in ovariectomized rats without changing bone formation. J. Bone Miner. Res. 19, 1144-1153 (2004).

9. Chalhoub, N. et al. Grey-lethal mutation induces severe malignant autosomal recessive osteopetrosis in mouse and human. Nat. Med. 9, 399-406. (2003).

10. Kasper, D. et al. Loss of the chloride channel ClC-7 leads to lysosomal storage disease and neurodegeneration. Embo. J. 24, 1079-1091 (2005).

11. Kornak, U. et al. Loss of the ClC-7 chloride channel leads to osteopetrosis in mice and man. Cell 104, 205-215 (2001).

12. Lange, P. F., Wartosch, L., Jentsch, T. J. \& Fuhrmann, J. C. ClC-7 requires Ostm1 as a beta-subunit to support bone resorption and lysosomal function. Nature 440, 220-223 (2006).

13. Pressey, S. N. et al. Distinct neuropathologic phenotypes after disrupting the chloride transport proteins ClC-6 or ClC-7/Ostm1. J Neuropathol Exp Neurol 69, 1228-1246.

14. Accardi, A., Kolmakova-Partensky, L., Williams, C. \& Miller, C. Ionic currents mediated by a prokaryotic homologue of $\mathrm{CLC} \mathrm{Cl}^{-}$channels. J. Gen. Physiol. 123, 109-119. (2004).

15. Zifarelli, G. \& Pusch, M. CLC chloride channels and transporters: a biophysical and physiological perspective. Rev. Physiol. Biochem. Pharmacol. 158, 23-76 (2007).
16. Jentsch, T. J. CLC chloride channels and transporters: from genes to protein structure, pathology and physiology. Crit. Rev. Biochem. Mol. Biol. 43, 3-36 (2008).

17. Stauber, T. \& Jentsch, T. J. Sorting motifs of the endosomal/lysosomal CLC chloride transporters. J. Biol. Chem. 285, 34537-34548 (2010).

18. Leisle, L., Ludwig, C. F., Wagner, F. A., Jentsch, T. J. \& Stauber, T. ClC-7 is a slowly voltage-gated $2 \mathrm{Cl}(-) / 1 \mathrm{H}(+)$-exchanger and requires Ostm1 for transport activity. Embo J 30, 2140-2152 (2011)

19. Scheel, O., Zdebik, A. A., Lourdel, S. \& Jentsch, T. J. Voltage-dependent electrogenic chloride/proton exchange by endosomal CLC proteins. Nature 436, 424-427 (2005)

20. Picollo, A. \& Pusch, M. Chloride/proton antiporter activity of mammalian CLC proteins ClC-4 and ClC-5. Nature 436, 420-423 (2005).

21. Accardi, A. \& Miller, C. Secondary active transport mediated by a prokaryotic homologue of $\mathrm{ClC} \mathrm{Cl}^{-}$channels. Nature 427, 803-807 (2004).

22. De Angeli, A. et al. The nitrate/proton antiporter AtCLCa mediates nitrate accumulation in plant vacuoles. Nature. 442, 939-942. (2006).

23. Jensen, V. K. et al. A quantitative assay for lysosomal acidification rates in human osteoclasts. Assay Drug Dev Technol 9, 157-164 (2011).

24. Arosio, D. et al. Simultaneous intracellular chloride and $\mathrm{pH}$ measurements using a GFP-based sensor. Nat. Methods 7, 516-518 (2010).

25. Costa, A. et al. The Arabidopsis central vacuole as an expression system for intracellular transporters: functional characterization of the $\mathrm{Cl}-/ \mathrm{H}+$ exchanger CLC-7. J Physiol 590, 3421-3430 (2012).

26. Trichas, G., Begbie, J. \& Srinivas, S. Use of the viral 2A peptide for bicistronic expression in transgenic mice. BMC Biol 6, 40 (2008).

27. Liantonio, A. et al. Molecular switch for CLC- $\mathrm{K} \mathrm{Cl}^{-}$channel block/activation: Optimal pharmacophoric requirements towards high-affinity ligands. Proc. Natl. Acad. Sci. U. S. A. 105, 1369-1373 (2008).

28. Steinmeyer, K. et al. Inactivation of muscle chloride channel by transposon insertion in myotonic mice. Nature 354, 304-308 (1991).

29. Estévez, R., Schroeder, B. C., Accardi, A., Jentsch, T. J. \& Pusch, M. Conservation of chloride channel structure revealed by an inhibitor binding site in $\mathrm{ClC}-1$. Neuron 38, 47-59 (2003).

30. Eggermont, J., Trouet, D., Carton, I. \& Nilius, B. Cellular function and control of volume-regulated anion channels. Cell. Biochem. Biophys. 35, 263-274 (2001).

31. Lingueglia, E., Champigny, G., Lazdunski, M. \& Barbry, P. Cloning of the amiloride-sensitive FMRFamide peptide-gated sodium channel. Nature 378, 730-733 (1995)

32. Liantonio, A. et al. Molecular requisites for drug binding to muscle CLC-1 and renal CLC-K channel revealed by the use of phenoxy-alkyl derivatives of 2(p- chlorophenoxy)propionic acid. Mol. Pharmacol. 62, 265-271 (2002).

33. Lorenz, C., Pusch, M. \& Jentsch, T. J. Heteromultimeric CLC chloride channels with novel properties. Proc. Natl. Acad. Sci. U. S. A. 93, 13362-13366 (1996).

\section{Acknowledgements}

We thank D. Arosio for the $\mathrm{E}^{2} \mathrm{GFP} / \mathrm{DsRed}$ clone, T.J. Jentsch for the WT clones of ClC-7 and Ostm1, E. Lingueglia for the FaNaCh clone, A. Gradogna and S. De Stefano for help with the oocyte injection, A. Liantonio and D. Conte Camerino for sharing chloride channel blockers, and F. Quartino, A. Barbin, and D. Magliozzi for technical assistance. The financial support by the Italian Institute of Technology (progetto SEED), Telethon Italy (grant GGP12008), the Italian Ministry of Education (progetto PRIN), and the Compagnia San Paolo is gratefully acknowledged.

\section{Author contributions}

M.P. and G.Z. conceived the project. M.P. and I.Z. planned and performed the experiments, analyzed the data, and wrote the manuscript.

\section{Additional information}

Supplementary information accompanies this paper at http://www.nature.com/ scientificreports

Competing financial interests: The authors declare no competing financial interests.

License: This work is licensed under a Creative Commons

Attribution-NonCommercial-NoDerivs 3.0 Unported License. To view a copy of this license, visit http://creativecommons.org/licenses/by-nc-nd/3.0/

How to cite this article: Zanardi, I., Zifarelli, G. \& Pusch, M. An optical assay of the transport activity of ClC-7. Sci. Rep. 3, 1231; DOI:10.1038/srep01231 (2013). 